\title{
Ustekinumab como alternativa terapéutica en la pustulosis plantar
}

\section{Ustekinumab as a therapeutic alternative in plantar pustulosis}

\author{
Aniza Giacaman*, Daniel Ramos-Rodríguez y Ana Martín-Santiago \\ Departamento de Dermatología, Hospital Universitari Son Espases, Palma de Mallorca, España
}

\section{Resumen}

No existe en la actualidad un tratamiento regular para la pustulosis palmoplantar (PPP), por lo que se utilizan diversas alternativas terapéuticas con resultados variables. Se presenta el caso de una paciente de 60 años que logró una respuesta favorable al tratamiento con ustekinumab, sin efectos secundarios durante el seguimiento.

Palabras clave: Pustulosis palmoplantar. Psoriasis. Tratamiento. Ustekinumab.

\begin{abstract}
Currently there is no a standard treatment for the palmoplantar pustulosis (PPP) and multiple therapeutic alternatives have been used with variables results. We present the case of a 60-year-old woman treated with Ustekinumab who achieve a good response. No adverse effects were detected during the follow-up.
\end{abstract}

Key words: Pustulosis of palms and soles. Psoriasis. Treatment. Ustekinumab.

\section{Introducción}

Hoy día no existe un tratamiento regular para la pustulosis palmoplantar (PPP), por lo que se utilizan diversas alternativas terapéuticas con resultados variables.

\section{Caso clínico}

Mujer de 60 años, fumadora, con antecedentes personales de asma, talasemia menor y dislipemia, que tenía una hermana gemela con PPP y artropatía psoriásica, y un hermano con eccema crónico de manos. Consultó por brotes recurrentes de pústulas y descamación en ambas plantas de más de 35 años de evolución que le provocaban dolor y dificultad para deambular (Fig. 1). La exploración física no mostró placas de psoriasis en el cuerpo ni refería artritis u otros síntomas sistémicos. Presentó escasa respuesta al tratamiento con corticoides tópicos y sistémicos, derivados de la vitamina $D$ e inmunomoduladores tópicos. Por la edad de la paciente, sus antecedentes patológicos como la dislipemia, las condiciones de su trabajo y los casos de pustulosis PPP descritos en las publicaciones médicas, se planteó la administración de ustekinumab, que se inició a dosis de $45 \mathrm{mg}$ a las 0 , 4 y 12 semanas. La evolución fue favorable, pero con
Correspondencia:

*Aniza Giacaman

E-mail: anizagiacaman@gmail.com
Disponible en internet: 06-10-2021 Med Cutan Iber Lat Am. 2021;49(Suppl 1):58-60 www.MedicinaCutanealLA.com 0210-5187/@ 2021 Colegio Ibero Latinoamericano de Dermatología A.C. (CILAD). Publicado por Permanyer. Este es un artículo open access bajo la licencia CC BY-NC-ND (http://creativecommons.org/licenses/by-nc-nd/4.0/). 


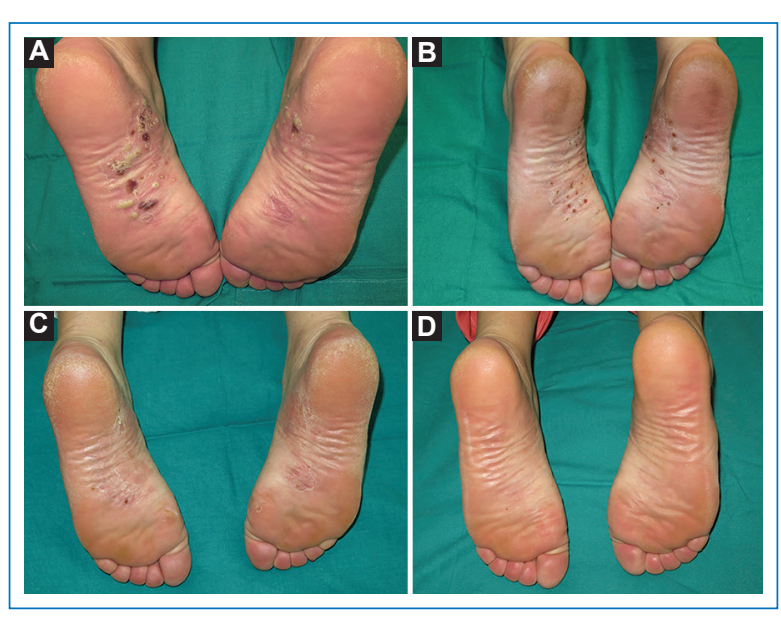

Figura 1. A: pústulas y descamación plantar antes de comenzar el tratamiento con ustekinumab. B: la misma paciente dos semanas después de la primera dosis de $45 \mathrm{mg}$ de ustekinumab. C: aparición de algunas pústulas plantares a las 12 semanas del tratamiento biológico. D: paciente sin lesiones que mantiene una pauta de tratamiento con intervalos de ocho semanas.

la aparición de nuevas pústulas los días anteriores a la siguiente dosis del tratamiento, por lo que se decidió acortar el intervalo entre las dosis a 10 semanas, luego a nueve y al final a ocho. Tras casi cuatro años de tratamiento con esta pauta se mantiene asintomática y no ha tenido efectos adversos significativos.

\section{Discusión}

La pustulosis palmoplantar es una entidad crónica y recurrente con una prevalencia calculada de $0.01 \%$ a $0.05 \%$. Se caracteriza por pústulas estériles relacionadas con lesiones eritemato-descamativas en palmas 0 plantas, casi siempre dolorosas, que pueden provocar gran repercusión en la calidad de vida. Algunos autores la consideran una entidad independiente, aunque hay otros que proponen que forma parte del espectro de la psoriasis'.

La PPP es más frecuente en mujeres de 40 a 60 años de edad y se ha descrito un nexo con el hábito tabáquico, así como con enfermedades del tiroides, síndrome metabólico, obesidad, diabetes y depresión ${ }^{1}$. La prevalencia de artritis varía entre $10 \%$ y $25.6 \%$ en pacientes con PPP. La relación con enfermedad celíaca no es concluyente, por lo que no se recomienda su cribado sistemático ${ }^{1}$.

La etiología de la PPP se desconoce y se propone la interacción de factores genéticos, la inmunidad innata, el microbioma y los factores ambientales.
Estudios recientes han demostrado que las vías de las IL-17 y la IL-36, con aumento de la expresión de la IL-8, intervienen en la etiopatogenia de esta enfer-

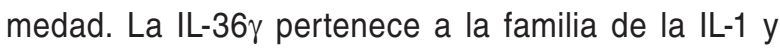
estimula la producción de IL-8 por parte de los queratinocitos. La IL-8 activa a la quimiotaxis de los neutrófilos e induce la formación de pústulas ${ }^{2}$. En algunos pacientes con PPP de inicio temprano, antes de los 40 años, se han detectado mutaciones en IL36RN. También se han descrito mutaciones en CARD14 en algunos pacientes de género masculino con PPP y sin antecedentes familiares de psoriasis. Por otra parte, no se ha encontrado vinculación significativa entre PPP y PSORS $1^{1}$.

La PPP es una afección de difícil tratamiento, ya que la respuesta a los tratamientos sistémicos típicos como fotoquimioterapia, ciclosporina, retinoides y metotrexato es en general escasa ${ }^{1}$. Durante los últimos años, el uso de fármacos biológicos ha surgido como una alternativa $^{3-6}$. El ustekinumab es un anticuerpo monoclonal humano que se une con alta especificidad y afinidad a la subunidad $\mathrm{p}-40$ de las interleucinas 12 y 23 y bloquea la diferenciación de los linfocitos $T$ colaboradores hacia Th1 y Th17, lo que reduce la liberación de IL-17 y por lo tanto la activación y migración de los neutrófi$\operatorname{los}^{2,4-6}$. Está indicado para psoriasis de moderada a grave y existen algunos casos descritos de pacientes con PPP tratados con ustekinumab que han obtenido respuestas favorables $\sin$ efectos adversos significativos, al utilizar dosis que varían entre 45 y $90 \mathrm{mg}$ subcutáneos, administrados entre ocho y 12 semanas. En la actualidad, otras alternativas terapéuticas incluyen guselkumab, etanercept, secukinumab, brodalumab, ixekizumab y apremilast ${ }^{3-6}$. Están en curso estudios clínicos con inhibidores de la IL-1 (anakinra), inhibidores del receptor tipo B de la IL-8 (RIST4721/AZD4721), inhibidor del receptor A de la IL-17 (brodalumab), inhibidores de la IL-36 (ANB019 y BI655,130) y un inhibidor del receptor del factor estimulador de colonias de granulocitos (CSL324), entre otros'.

\section{Conclusión}

Los tratamientos biológicos pueden ser útiles en pacientes con PPP grave, resistentes a los tratamientos sistémicos o con afecciones concomitantes. La dosis del tratamiento puede ser variable en cada paciente y es importante ajustarla según sean la respuesta clínica y la evolución de la enfermedad. 


\section{Financiamiento}

Los autores declaran que no han recibido financiamiento para la elaboración del manuscrito.

\section{Conflicto de intereses}

Los autores declaran no tener ningún conflicto de intereses.

\section{Responsabilidades éticas}

Protección de personas y animales. Los autores declaran que para esta investigación no se han realizado experimentos en seres humanos ni en animales.

Confidencialidad de los datos. Los autores declaran que han seguido los protocolos de su centro de trabajo sobre la publicación de datos de pacientes.
Derecho a la privacidad y consentimiento informado. Los autores han obtenido el consentimiento informado de los pacientes y/o sujetos referidos en el artículo. Este documento obra en poder del autor de correspondencia.

\section{Bibliografía}

1. Misiak-Galazka M, Wolska H, Rudnicka L. What do we know about palmoplantar pustulosis? J Eur Acad Dermatol Venereol. 2017 Jan;31:38-44

2. Misiak-Galazka M, Zozula J, Rudnicka L. Palmoplantar pustulosis: recent advances in etiopathogenesis and emerging treatments. Am J Clin Dermatol. 2020 Jun;21:355-370.

3. Husson B, Barbe C, Hegazy S, Seneschal J, Aubin F, Mahe E, et al. Efficacy and safety of TNF blockers and of ustekinumab in palmoplantar pustulosis and in acrodermatitis continua of Hallopeau. J Eur Acad Dermatol Venereol. 2020 Feb 6.

4. Morales-Munera C, Vilarrasa E, Puig L. Efficacy of ustekinumab in refractory palmoplantar pustular psoriasis. Br J Dermatol. 2013 Apr;168:820-824.

5. de Unamuno-Bustos B, Ballester-Sánchez R, Oliver-Martínez V, Alegre de Miquel V. Ustekinumab for the treatment of palmar-plantar pustulosis. Actas Dermosifiliogr. 2011 Dec;102:833-835.

6. Gerdes S, Franke J, Domm S, Mrowietz U. Ustekinumab in the treatment of palmoplantar pustulosis. Br J Dermatol. 2010 Nov;163:1116-1118. 